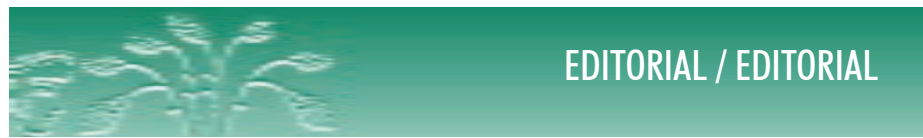

DOI: http://dx.doi.org/10.12957/demetra.2014.11953

\title{
Necessidades alimentares especiais: o cuidado e a busca da equidade na atenção à saúde
}

\section{Special dietary needs: the care and pursuit for equity in health assistance}

As necessidades alimentares especiais são uma realidade para parcelas expressivas da população brasileira. Entretanto, permanecem invisíveis e/ou secundarizadas na agenda da saúde. A construção e a garantia da atenção qualificada às pessoas com essas necessidades devem ser assumidas como fundamentais para a construção da equidade no cuidado em saúde.

Nesse contexto, para nós foi uma honra organizar este número dedicado ao tema "Atenção às necessidades alimentares especiais no Sistema Único de Saúde (SUS), fruto da parceria entre a Revista Demetra, a Coordenação-Geral de Alimentação e Nutrição (CGAN) do Ministério da Saúde e a Organização Pan-Americana da Saúde (OPAS). O objetivo é contribuir para superar a escassez de publicações e subsidiar gestores e profissionais para a organização e oferta do cuidado no SUS às pessoas que apresentam algum tipo de necessidade alimentar especial.

No processo de produção deste número especial, contamos com a inestimável colaboração de Kelly Poliany de Souza Alves (CGAN), Kimielle Cristina Silva (CGAN) e Ana Carolina Feldenheimer Silva (Organização Pan-Americana da Saúde, Brasil), a quem registramos nossos agradecimentos. 
Recebemos 28 trabalhos advindos de diferentes regiões do país e que abrangeram estudos, relatos de experiência e ensaios, desenvolvidos por profissionais de serviços de saúde (em parceria ou não com a universidade), pesquisadores, professores e ativistas. Destes, 13 foram pré-selecionados e 11 concluíram o processo de revisão. Os artigos aqui reunidos versam sobre os seguintes temas: organização do cuidado nas Redes de Atenção à Saúde; estudos epidemiológicos sobre consumo alimentar de indivíduos com necessidades alimentares especiais; descrição e avaliação de inovações em terapia nutricional; formulações para uso em vias alternativas de alimentação; terapia nutricional domiciliar; estratégias de formação e qualificação dos profissionais de saúde; ferramentas, procedimentos e técnicas para o cuidado; judicialização dos direitos à saúde e à alimentação; e questões subjetivas e objetivas das pessoas que apresentam necessidades alimentares especiais.

Este número especial representa, portanto, um esforço pioneiro de sistematização do que vem sendo produzido sobre o tema no Brasil e, em particular no (e para o) SUS. Há muito que avançar, ainda, em relação aos temas acima listados e a outros, como por exemplo: eficácia de dietas para fins específicos; questões éticas e conflitos de interesses na prescrição de fórmulas nutricionais; prevalência em âmbito municipal, estadual ou regional de condições que geram necessidades alimentares especiais; relações das pessoas com necessidades especiais com seus cuidadores e com os profissionais de saúde. Há que se avançar, também, no registro das experiências que vêm sendo acumuladas em diversas realidades em nosso país.

Um passo importante na direção da superação dos desafios que estão postos nessa área é reconhecer as necessidades alimentares especiais como tema transversal e convergente não somente entre as diversas áreas da Nutrição (Clínica, Saúde Coletiva, Dietética, Ciência de Alimentos, Alimentação Coletiva), mas também entre as diversas áreas da saúde. Que este número sirva como inspiração para a construção de agendas e esforços conjuntos de atores inseridos em diversos âmbitos, entre eles o da formação dos profissionais de saúde, o da produção do conhecimento e o da organização da atenção nutricional no Sistema Único de Saúde.

Luciana Maria Cerqueira Castro

Professora adjunta - Instituto de Nutrição - Universidade do Estado do Rio de Janeiro - UERJ

Inês Rugani Ribeiro de Castro

Professora associada - Instituto de Nutrição - Universidade do Estado do Rio de Janeiro - UERJ 